\title{
Scientific Ontology: Fact or Stance?
}

\author{
STATHIS PSILLOS (D) University of Athens
}

ABSTRACT: In this paper, the key tenets of Anjan Chakravartty's book Scientific Ontology are critically discussed. After a brief presentation of the project of stancebased ontology (Section 2), I move on to criticize Chakravartty's account of metaphysical inference (Sections 2 and 3). Then, in Section 4, I take issue with Chakravartty's view that fundamental debates in metaphysics inevitably lead to irresolvable disagreement, while in Section 5, the concept of epistemic stance is scrutinized, noting that there are problems in Chakravartty's account of the rationality of stance-choice. Finally, Section 6 is about the implications of stance-based ontology for the scientific realism debate.

RÉSUMÉ: Dans cette contribution, les points fondamentaux du livre d'Anjan Chakravartty, Scientific Ontology, sont discutés de manière critique. Après une brève présentation du projet d'une ontologie dite «stance-based» (section 2), je critique la manière dont Chakravartty conçoit l'inférence métaphysique (sections 2 et 3). Puis, dans la section 4, je conteste l'opinion de Chakravartty selon laquelle les débats fondamentaux en métaphysique conduisent inévitablement à un désaccord insoluble. La section 5 examine le concept de position épistémique et relève les problèmes inhérents à la manière dont Chakravartty conçoit la rationalité de la sélection d'une position. Finalement, la section 6 concerne les implications d'une ontologie qui serait basée sur les positions épistémiques («stance-based») pour le débat sur le réalisme scientifique.

Keywords: Chakravartty, metaphysics, Newton, explanation, scientific realism, empiricism

Dialogue 60 (2021), 15-31

(C) The Author(s), 2021. Published by Cambridge University Press on behalf of the Canadian Philosophical Association/l'Association canadienne de philosophie. This is an Open Access article, distributed under the terms of the Creative Commons Attribution licence (http://creativecommons.org/licenses/by/4.0/), which permits unrestricted re-use, distribution, and reproduction in any medium, provided the original work is properly cited.

doi:10.1017/S0012217320000360 


\section{The Project: Stance-Based Ontology}

Once upon a time, W.V. Quine asked the famous question, which consists of three monosyllables: What is there? To which he answered: Everything! As he immediately noted, however, that's more or less tautological: there is what there is. ${ }^{1}$ Ontology, or the theory of Being and its kinds, is possible precisely because there is substantial disagreement as to what there is.

In Scientific Ontology (henceforth SO), Anjan Chakravartty (henceforth AC) takes the three-word ontological question and applies it to science: What is there, according to science? The obvious answer, of course, is: 'everything science says there is.' But here the issue is not so much the tautological content of this answer, since there is no obvious tautology in the claim: 'there is what science says there is.' The problem is to figure out what science says there is. First, at the level of the kinds of things there are in the world. For instance, are there tectonic plates? Are there DNA molecules? Were there dinosaurs? and the like. Second, at the level of the ontic categories that constitute the metaphysical blueprint of Being. For instance, are there universals or is everything there is particular? Are there abstract entities or is everything there is concrete? Are there irreducible causal powers or is everything there is passive and subject to universal laws?

The two levels, though connected, are distinct. To see the difference clearly, we have to go back to Aristotle and his characterization of first philosophy (what has come to be known as 'metaphysics') as the science of being qua being and of "the attributes which belong to this [the Being] in virtue of its own nature." Of the various particular sciences, Aristotle says, none studies the Being as such. Rather, each particular science (Aristotle refers explicitly to physics and maths) cuts off a part of Being ( $\dot{\alpha} \lambda \lambda \dot{\alpha} \mu \varepsilon \dot{\varepsilon} \rho o \varsigma \alpha \dot{v} \tau o \hat{v} \tau \iota \dot{\alpha} \pi o \tau \epsilon \mu o ́ \mu \epsilon v \alpha l)$ and investigates the attributes of this part (1003a22-1003a32). The domain of each science, then, is some part of Being (e.g., matter in motion, biological processes, etc.), while metaphysics studies Being as such. Each science has its own peculiar ontology but metaphysics studies ontology as such, viz., the pure categories of Being.

Hence, it is one thing to be committed to, say, electrons but it is quite another thing to be committed to, say, electronhood (qua a universal shared by all and only electrons). Similarly, it is one thing to be committed to, say, apoptosis as the causal pathway (and hence the mechanism) of programmed cell death, while it is another thing to be committed to Mechanisms, qua a distinct causally operative structure of entities and activities. A key issue here is whether looking directly to science (the various theories and practices) can cast any light on questions of the second level. Things are complicated further by the fact that at least some of the first-level issues cannot be settled by looking directly to science either.

$1 \quad$ See Quine, 1948. 
Hence, there are two broad philosophical problems:

- What exactly does scientific ontology consist in?

- What are the grounds for settling questions of scientific ontology?

$\mathrm{AC}$ draws the distinction between the two levels of commitment in terms of a contrast between explicit ontology and implicit ontology. The explicit ontology captures the explicit subject matters of scientific investigation: what the theory is about (e.g., genes, electrons, tectonic plates, coronaviruses, quantum fields, etc.). The implicit ontology, being implicit in a theory, is not read directly from the explicit subject matter of the theory (e.g., electrons) but concerns roughly what Aristotle called the "categories" (attributes), which belong to Being "in virtue of its own nature": properties, causal relations, laws of nature, possibilities and necessities, and so on. AC is, of course, aware of the fact that at least some of the denizens of the implicit ontology are spoken of by the scientific theory. A theory might well make reference to properties, laws and causes, dispositions, possibilities, and the like. But AC notes that these entities are "not the face-value targets of scientific work."

Here, then, is the main thesis of SO. The two problems/questions noted above cannot be settled unless they are linked with questions and issues in epistemology; that is, with what we have warranted beliefs about. However, empirical evidence massively underdetermines ontology, especially the implicit one. (For instance: can there be empirical evidence about the existence or not of irreducible dispositions? It seems very unlikely.) How are we to proceed, then? Ontological questions are settled by adopting epistemic stances. As AC puts it: "no stance in, no ontology out.",

If what we say there is (and, ultimately, what there is) depends on (the adoption of) an epistemic stance, what kinds of things are stances? Now, it is well known that the notion of a stance has been previously defended by Bas van Fraassen as a non-doxastic cluster of propositional and non-propositional elements. ${ }^{4} \mathrm{AC}$ adopts this stance talk: stances are not beliefs - they are neither true nor false; stances are occupiable; they involve values and intentions. As AC put it: "A stance is an orientation, a cluster of attitudes, commitments, and strategies relevant to the production of allegedly factual beliefs." A stance, then, sounds like a blueprint for an epistemic policy.

Here is the critical part then. Given that what there is depends on what epistemic policy is adopted, how are epistemic policies (and hence stances) chosen?

\footnotetext{
2 Chakravartty, 2017, 69.

3 Ibid., 65-66.

4 van Fraassen, 2002.

5 Chakravartty, 2017, 47.
} 
Voluntarism is the answer AC offers, subject to the norm of naturalized metaphysics: "scientific ontology is properly delimited by metaphysical inferences and propositions that are sufficiently informed by or sensitive to scientific-empirical investigation." 6

\section{What Is a Metaphysical Inference?}

AC says:

Reasoning in metaphysics from data to conclusions - the process of making inferences - has a significant a priori dimension. That is, it is reasoning that is fueled primarily by non-empirical considerations, as opposed to empirical or a posteriori considerations, ones that are directly informed by or especially sensitive to observations and experiences. Commonly, the largely non-empirical considerations involved in making metaphysical inferences are explanatory: thoughts about how best to optimize the sorts of features often associated with good explanations. ${ }^{7}$

It transpires that metaphysical inferences are circumscribed as such by being explanatory, where the explanatory considerations are taken to be, typically at least, non-empirical (and hence a priori). But this claim is very odd. Explanatory considerations and the accompanying theoretical virtues might well be given an a priori justification. But relying on them need not be justified in a non-empirical manner; rather, their justification might well be a posteriori, viz., how they have contributed to the acceptance of well-founded theories. ${ }^{8}$ Besides, what exactly is it for an inference to be "fueled" by "empirical or a posteriori considerations, ones that are directly informed by or especially sensitive to observations and experiences"? Typically, an inference is "fueled" by the rule that underwrites it. And what matters is not the premises of the inference, but rather its justification. Even induction - which is closest to being informed by empirical premises - requires justification.

AC argues: "Typically, the goal of a metaphysical inference is to provide an explanatory account of some observable phenomenon or phenomena in terms of some underlying, unobservable thing or things." I think that even Isaac Newton, whose overall anti-metaphysical credentials are hardly deniable, would balk at this. Recall one of his most famous pronouncements: "And it is enough that gravity really exists and acts according to the laws that we have set forth and is sufficient to explain all the motions of the heavenly bodies and of our sea." ${ }^{10}$ Gravity is an unobservable 'thing' that offers an explanatory

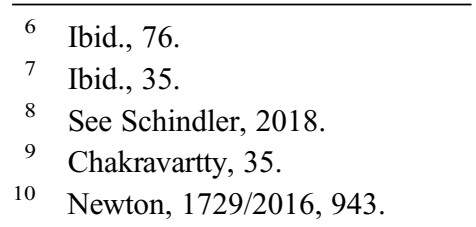


account of some observable phenomena, viz., the planetary motions, the motion of the moon around the earth and the fall of the bodies near the surface of the earth.

Was gravity, then, qua an explanatory posit, a metaphysical posit? And wouldn't that go against Newton's own account of a metaphysical posit? ${ }^{11}$ More generally, AC's account of metaphysical inference would end up rendering almost all unobservable entities metaphysical posits. But, the reader might note, didn't Newton refrain from explaining the cause of gravity. That's true but irrelevant to the point I am trying to make. And the point is this: scientific Inference is based on explanatory considerations; it aims at explaining (but not necessarily fully explaining) the phenomena by reference to unobservable entities. Causal scientific explanation is explanation in terms of unobservables. The issue is not so much whether explanatory considerations are involved in scientific inference. Rather, the issue is what counts as the best explanation of the evidence and why, or better under what circumstances and conditions, it is truth-tracking.

Actually, the point just made about scientific inference could be extended to common-sense inferences to observables, which too are based on explanatory considerations. It has been argued (by Quine, to name but one) that the very idea that there are middle-sized material objects is accepted on the basis that it offers the best explanation of the patterns in our sensory contents (sense data, etc.). ${ }^{12}$

If, qua explanatory, all these inferences (scientific and common-sense) were metaphysical inferences, then it's metaphysical inferences all the way up and all the way down! Metaphysics is everywhere! AC's distinction between metaphysical and scientific inference is trivialized in this way. I conclude that no useful category is captured by the expression 'metaphysical inference.'

11 As is well known, Newton distinguished, quite sharply, between an explanatory posit and a metaphysical one. The latter goes beyond whatever can be deduced from the phenomena and made general by induction in being irreducibly hypothetical, i.e., speculative. The cause of gravity is a case in point. Newton considered it enough that he identified the law that gravity obeys. The fact, if it is a fact, that there is a hitherto unknown 'cause' of gravity does not detract from the fact that he identified gravity as "the force by which the moon is kept in its orbit." His agnosticism as to the physical seat of gravity neither renders the law a mere calculating device nor prevents Newton from stressing that gravity "really exists." To get an explanatory posit, as opposed to a metaphysical one, is to use the phenomena (which are empirical structures) as premises such that, together with the general laws of motion, further laws are derived on their basis. What is thereby derived is not speculative and unfounded.

See Psillos, 2004. 


\section{Little $\mathbf{m} / \mathbf{B i g} \mathbf{M}$}

$\mathrm{AC}$ has another go. He argues that "there is something like a continuum ranging from lesser to greater magnitudes of metaphysical inference," and though he claims that "There is no boundary" in the continuum of the "magnitude" of metaphysical inference, he also thinks there is a kind of criterion distinguishing between big M Metaphysical claims and small m metaphysical claims: "The greater the use of metaphysical inference to get from the commonplace to the less familiar, the more likely it is, it seems, to fall on the side of being labeled with a capital $\mathrm{M}$ '."13

This "continuum" hypothesis creates the impression of a distance function which determines the "magnitude" of metaphysical inference. But distance from where? The reference point to which all metaphysical inferences are drawn to is "empirical inquiry." Then, "Exercises in scientific ontology can be closer to or further away from this point of reference, hence the notion of distance." 14

I think $\mathrm{AC}$ would agree that there is no such thing as the empirical inquiry, pure and simple. Empirical inquiry is imbued with metaphysical presuppositions. Still, according to AC, the "distance" is a function of two criteria:

(EV) empirical vulnerability: how susceptible a proposition is to empirical testing, and

(EP) explanatory power: how well a metaphysical inference or resulting proposition satisfies the criteria typically associated with good explanations. ${ }^{15}$

The two criteria taken together define epistemic risk. A first preliminary point, viz., that testing is holistic, already reveals a problem. We all know now something that Pierre Duhem and Quine made clear, viz., any proposition is, in principle, susceptible to empirical testing, by being embedded in a system which is testable and hence revisable as a whole. Even Capital M propositions are testable, in this sense, despite Rudolph Carnap's special effort to show how they can be treated as isolated sentences. ${ }^{16}$

A second preliminary point is in order: these two criteria need to be balanced and there may be scientific cases in which explanatory power trumps empirical vulnerability. Take the theory of quarks. The hypothesis that quarks are real entities satisfies (EP) but not so much (EV).

Given the two criteria and the two preliminary points, it appears that there is no real difference in the epistemic risk involved in testing ordinary scientific claims (small m posits) and claims about 'remote' or 'exotic' entities (Capital

\footnotetext{
13 Chakravartty, 2017, 52.

14 Ibid., 83.

15 Ibid., 85, 87.

16 Carnap, 1956.
} 
$\mathrm{M}$ posits). Besides, if these criteria count as criteria of rational belief, it follows that belief in 'exotic' entities is just as rational as belief in ordinary scientific posits, provided the right balance is struck between the two criteria. Actually, relative to a phenomenalist or a Berkeleyan idealist, ordinary beliefs about material objects (the empirical basis of science, as it were) are licensed by these two criteria (especially the second).

Hence, all beliefs about entities other than sense data (if there are any of those) are epistemically risky and yet rational. Whether they are equally risky, is irrelevant, since the 'strength' of the risk taken is not fixed algorithmically.

Now to avoid misunderstanding, I should note that, though I have defended and still defend Inference to the Best Explanation (henceforth IBE) and explanation-based reasoning and inference in general), I have also argued that IBE should be used with extra caution when it comes to cases concerning what I called above second-level ontological claims, viz., the level of the ontic categories that constitute the metaphysical blueprint of Being. The reason is that when IBE is used in science there are a number of extra checks and balances available that can cast further support or doubt on the chosen best explanations. Most of these extras are missing when it comes to the use of IBE in metaphysics. So, I think AC is right when, towards the end of SO, he says that for metaphysical claims to command belief, they should be "informed by or sensitive to the evidence of (scientific) observation, detection, experimentation, and explanatory practice." ${ }^{\prime 17}$ So, what's the point of my argument in this section? It is simply that all of our beliefs (be they scientific, metaphysical, or everyday) should be informed by or be sensitive to the evidence of observation, detection, experimentation, and explanation. In this sense, whether a posit is big $\mathrm{M}$ or small $\mathrm{m}$ makes no difference. What makes a difference is the evidence there is for any kind of claim we care to make.

\section{The Debate within Metaphysics: Coherence vs. Plausibility}

What is the outcome of metaphysical disputes about fundamental ontology? They are led "inevitably to irresolvable disagreement," says AC. ${ }^{18}$

Take, for instance, the debate concerning structuralism. The structuralist view is that, crudely put, all there is is structure - that is, networks of relations, where the nodes of the structure are 'reconceptualized' as objects. It then bifurcates into eliminative structuralism and non-eliminative structuralism. On the first, there are no objects, only relations; on the second, objects are not eliminated, but still they get their identity conditions (only) through relations. The contrast between the eliminativist view and the non-eliminativist is based on the plausibility of the view that relations do not require relata (relations-without-relata) and the plausibility of the view that there are entities but having no intrinsic

\footnotetext{
17 Chakravartty, 2017, 246.

18 Ibid., 148.
} 


\section{Dialogue}

nature. In either case, the locus of causation is relocated to the relations (whatever that means).

How should we assess the situation and choose among the two versions? AC's answer is that this kind of situation captures the limits of metaphysical theorizing. It doesn't call for further reasons or evidence, but rather for a choice of stance. Recall (lest we forget) that:

A stance is not something for which one gives justifications as such, but rather something that one adopts because it reflects what one values, epistemically. It is foundational in a manner of speaking, but beyond meeting the basic constraint of rationality, it is not something to be justified so much as an expression of self. ${ }^{19}$

$\mathrm{AC}$ presents his case by devising the following dilemma:

A. "Given a version of structuralism, one determines the locus/loci of causal efficacy.

B. In evaluating the tenability of this view, one faces a metaphysical challenge.

C. In replying to the challenge, one posits a contentious ontological primitive.

D. Dilemma: accept the contentious posit, or reject this version of structuralism." 20

Actually, this pattern of reasoning can be taken to capture a general schema in metaphysical theorizing:

MT

A. Metaphysical thesis X entails Y.

B. In evaluating the tenability of $\mathrm{X}$, one faces a metaphysical challenge as to $Y$.

C. In replying to the challenge, one posits a contentious ontological primitive.

D. Dilemma: accept the contentious posit, or reject X.

AC's point is that these dilemmas do not call for a reasoned resolution. Rather they are "identifiers of branching points, or decision points, in scientific

$\begin{array}{ll}19 & \text { Ibid., } 242 . \\ 20 & \text { Ibid., } 149 .\end{array}$ 
ontology." ${ }^{21}$ So, roughly put, we pick up one of the horns and we go. However, a key question here is this: when faced with a metaphysical dilemma of this sort, are both horns equally compelling? Aren't there rational ways to prefer one over the other? Or to dismiss some common presupposition?

The case of structuralism is instructive. AC - a well-known critic of structuralism - identifies the key problems faced by structuralism, vis-à-vis causation. In the case of eliminative structuralism, the problem is how in the first place abstract (mathematical) structure can be causal. In the case of non-eliminative structuralism, the problem is, assuming that there is a thingy with no intrinsic nature that stands in (extrinsic) relations with other thingies, what is this thingy? Though there is no space for developing this point properly, I don't see why this situation calls for a(n) (arbitrary) choice as opposed to claiming that there is a reasonable resolution of the dilemma, viz., to reject the common presupposition, viz. structuralism. ${ }^{22}$ Hence, either structuralism and causation do not mix, or a more robust conception of objects is required.

To make this point that metaphysical rivalry can be dealt with in a reasonable manner, let us briefly look at another instance of schema (MT) above.

A. The view that laws are necessitating relations among universals (X) entails that laws are distinct from the regularities there are in the world (Y).

B. In evaluating the tenability of this view, we face the challenge of explaining how laws yield the regularities.

C. In replying to this challenge, the advocates of the view posit a relation of causation among properties.

D. Dilemma: either accept this new posit or reject the view that laws are necessitating relations among universals.

The case of the necessitarian conception of laws is instructive, because as is well-known, the new ontological posit - the relation of necessitation - fails to account for what it is means to account for, viz., the regularity there is in the world. And this is a good reason to reject the necessitarian conception of laws.

It is certainly true that any position can be held, come what may, by making suitable adjustments elsewhere in the system and/or introducing primitives. It is also true that if the only criterion of success in metaphysical theorizing is coherence, then there is not much room for a rational resolution of deep disagreements. But, like in science, metaphysical theorizing must be subjected to

21 Ibid., 161.

22 There is a perfectly plausible and general argument for this dilemma, which, if correct, would render structuralism implausible (see Psillos, 2006). 
plausibility judgements as well as judgements of unification and other theoretical virtues. Ultimately, the matter is resolved with an explanatory cost-benefit analysis. AC says:

The moral is this: it is in the nature of scientific ontology that one may contest the inferences made at any point along the spectrum of metaphysical inference. It is the fact that different agents do so at different points that serves as one of the major determinants of different conceptions of scientific ontology, reflecting prior epistemic stances. ${ }^{23}$

Three points are worth making in relation to this:

- First, AC is right. Inferences to elements of scientific ontology can be contested at many points, starting from the level of ordinary material objects (phenomenalists do contest them) and finishing at the level of 'exotic' entities, like causal powers or entities without intrinsic natures.

- But, second, not all ways to contest elements of scientific ontology are equally reasonable and compelling. For instance, despite the fact that creationists challenge evolutionary theory and almost all of its ontology, there are excellent reasons to accept Darwinian evolution and its mechanisms.

- And, third, the fact that different agents choose to stop at different points does not make all these choices equally reasonable.

\section{How Are Stances Chosen?}

This last point needs further elaboration. What are the criteria of reasonableness? To address this issue, let us broaden it a bit and ask the super-critical question: Are all choices of stance equally reasonable?

AC singles out three epistemic stances: the deflationary stance, the empiricist stance, and the metaphysical stance. The metaphysical stance licenses explanations of the observable phenomena, where these explanations proceed by positing unobservable causes and mechanisms. The empiricist stance, which AC associates (too quickly, in my view) with empiricism, represents a more cautious approach to ontology, allowing detection by our unaided senses to be, by and large, the criterion of ontic commitment. Interestingly, AC takes the empiricist stance to be a sceptical stance, which suggests suspension of judgement as opposed to outright disbelief in the existence of unobservable entities. ${ }^{24}$ Finally, the deflationary stance does not take ontology seriously as a putative description of the kinds of Being there are. Rather, it typically paraphrases or dissolves ontological claims as claims about the use of language, or about the

\footnotetext{
23 Chakravartty, 2017, 161.
}

24 Ibid., 50. 
socially conditioned and historically changing frameworks that people use to construct their theoretical accounts of the world. Recall (lest we forget) that a stance is a complex non-doxastic cluster of attitudes, whilst an epistemic stance relates to the adoption of an epistemic policy - that is, an account of the relation between evidence and theory, of the limits of warrant, of the structure of evidence-based-inference, and so on. Accordingly, the metaphysical stance is more inclusive and permissive than the empirical stance.

So, we have three major stances and a dispute between them. What is the subject of the dispute? Ultimately, it should be the world and its denizens. The relatively "expansive ontological ambitions",25 of those who adopt a metaphysical stance are, I should think, based on the claim (better, the belief) that a more "austere" 26 account would leave important content of the world out of our grasp. Not so much because we are unable to grasp it but because, by adopting an empiricist stance, we preclude ourselves from asking the further questions and devising and testing the theories that might well be revealing to us this hitherto unseen content (electrons, tectonic plates, coronaviruses etc.). At the same time, the more austere ambitions of those who occupy the empiricist stance are, typically, based on the claim (better, the belief) that the limits of our sensory experience are the limits of our knowledge of the world, and that all the rest are mere metaphysical speculations. (A propos, I doubt that actual empiricists have occupied this stance, but that's a different story.)

For AC, beliefs depend on stances; hence, first the stance, then the belief. Here is how AC puts the point: "there is something voluntary in the adoption of stances, and it is stances that in part determine our doxastic states, in virtue of the attitudes, orientations, and epistemic policies they afford regarding whether certain kinds of ontological propositions are amenable to belief." 27

Or is it, as I insinuated above by italicizing belief, the other way around? That is, first the belief, then the stance. For instance, X doesn't believe in atoms (for various reasons) and hence $\mathrm{X}$ adopts a stance towards theories that is licensed by this belief, e.g., instrumentalism. Or Y doesn't believe that there is (substantive) knowledge independently of the senses, hence Y adopts a stance towards knowledge that is licensed by this belief, e.g., empiricism. So, I think, one's epistemic policies are grounded on one's beliefs and not the other way around. ${ }^{28}$

How can we tell the order of dependence, then? Do beliefs depend on stances or stances on beliefs? It's really hard to answer especially descriptively. But, if

\footnotetext{
25 Ibid., 212.

26 Ibid., 47, 210.

27 Ibid., 219.

28 I think this point is a lot more obvious if we talk about social and political beliefs and corresponding stances, e.g., 'I believe in social justice, therefore I occupy stance S,' or 'I don't believe in God, therefore I occupy stance Q.' But I leave it to the reader to work out the various cases.
} 
we look at the matter normatively, things look a lot different. For, after all, we would want to pick reasonable stances and not any stance. But reasonableness applies to an attitude with propositional content, since evidence can bear on the content. Hence, it's plausible to think that the very idea of adjudicating among stances, as opposed to merely occupying them, requires, to say the least, that stances contain or presuppose enough belief content which, being propositional, can be assessed by reason and evidence. If this is the case, then stances can be justified or unjustified and can be rational or irrational, according to whether the beliefs that license them are justified, etc. Epistemology proper takes over in offering accounts of the warrant of the beliefs that constitute the stance.

Hence, I think AC puts the cart before the horse when he emphatically insists:

[S]tances are not subject to belief, disbelief, or agnosticism. Stances are not claims about the world but rather collections of attitudes, commitments, and strategies that determine how one goes about producing ontological claims. As such, they are not believed (disbelieved, etc.) but rather adopted and exemplified in attempts to generate putative knowledge. $^{29}$

The emphasis here should be on the "putative," since knowledge requires justification and we have not yet been told anything about how belief is justified (let alone true).

Is this an exaggeration in a book that talks about an epistemic stance being "relevant to understanding how purported knowledge of scientific ontology is generated"? ${ }^{30}$ I am afraid it is not. Of the 13 occurrences of the word "justification" in the book, only one might be tangentially relevant to the issue of how belief or disbelief in (some parts of) scientific ontology is justified. In the passage I have in mind, AC raises the "lingering concern that having granted the importance of contexts in scientific investigation, justification, and the resulting generation of knowledge, I have made scientific ontology somehow dependent on human thoughts, actions, and intentions after all." 31 The subsequent four pages are perhaps the most critical and the vaguest in the whole book. AC becomes uncharacteristically blurry. The issue is not context. He is clearly right in saying that ontological packages may play different roles in different contexts. The issue is: are we getting the world right (or more right than before)? In other words, are there, say, electrons or not? And, moreover, are there, say, universals or not? That I might be allowed to talk about electrons and/or universals (that is, use the relevant words in my discourse) if I adopt a metaphysical stance does not cast much light on questions such as those above.

\footnotetext{
29 Chakravartty, 2017, 206.

30 Ibid., 206.

31 Ibid., 196.
} 
In fact, if adopting a stance is governed by voluntarism, there cannot be any knowledge. 'I do voluntarily believe that $p$; hence I know that $p$ ' is a fallacy. And so is 'I do voluntarily believe that $p$; hence $p$.' AC knows all this very well. He therefore warns us: "Voluntarism in epistemology is not a license to behave carelessly or erratically when it comes to belief." 32 Two are the criteria for rational stance-choice:

- Coherence (deductive/probabilistic), and

- No self-sabotage (no self-defeating).

Coherence is obviously necessary but not sufficient for rationality. A coherent set of beliefs (e.g., in flat earth) is not necessarily rational. In any case, coherence applies to states with propositional content (beliefs) and not to stances.

Self-sabotage (or shooting oneself in the foot) is a situation one is in when one adopts beliefs that are self-defeating, that have no chance of being vindicated. As van Fraassen puts it: "a minimal criterion for reasonableness is that you should not sabotage your possibilities of vindication beforehand." 33 AC puts it thus:

[A] rational stance is one that does not lead inexorably to beliefs that are in tension with the attitudes and orientations that constitute the stance itself, since subscribing to such a combination would be self-defeating and thus pragmatically incoherent. ${ }^{34}$

Here, again, the no-self-sabotage principle is not enough for rationality. Creationism is not self-defeating. Yet, it is not necessarily rational.

If the two criteria for rational stance-choice fail to circumscribe all and only rational stances, how are "epistemically pathological stances" 35 ruled out? AC gives such a precedence to stances over beliefs that "even a demonstration of false or inconsistent beliefs would not by itself demonstrate the incoherence

32 Ibid., 223.

33 van Fraassen, 1989, 157.

34 Chakravartty, 2017, 224. According to Bernard Williams, 1973, it is (pragmatically) incoherent to say that I believe at will. Belief aims (constitutively) at truth. If I could acquire a belief at will, then I could acquire it whether it was true or not. Being $m y$ belief, I take it to be true. But I also know that my belief could be acquired whether it was true or not. Hence, I am (pragmatically) incoherent. I am saying: 'I believe that $p$ (is true) but I believe that $p$ whether it is true or not.' This is not a formal contradiction, as it can be easily seen if we replace the 'I' with a 'she': 'she believes that $p$ (is true) but she believes that $p$ whether it is true or not' might well be true. Yet, when this sentence is uttered by $m e$, it is (pragmatically) incoherent.

35 Chakravartty, 2017, 224. 
of an associated stance." 36 This seems to allow all kinds of pathological stances and moreover to undermine the very idea of coherence as a necessary condition of rationality: even if a set of beliefs were incoherent, it wouldn't follow that the associated stance was irrational.

Taking issue with my own earlier critique of voluntarism, and in particular my claim that voluntarism fails to incorporate a proper deference to evidence in the form of a commitment to "regard all evidence that bears on a certain belief (or hypothesis) judiciously," AC reminds us that he takes "stance" to mean "epistemic stance" and asks: "How could an epistemic stance permit a disregard for evidence, given that evidence is, by definition, anything that serves to indicate, confirm, corroborate, or prove the truth or falsity of a proposition?"37

But, if a stance is a license for an epistemic policy, and if the adoption of a stance is, even ultimately, a matter of the will (and not of reason and evidence), then it's perfectly possible for a stance to license disregarding (some) evidence. After all, it is an aspect of an epistemic policy to determine what counts as evidence in particular as relevant evidence. Hence, the injunction might have the sophisticated form 'disregard irrelevant evidence'; but the devil is in the details of relevance. For instance, van Fraassen thinks that images seen under a microscope are not copy-qualified images (i.e., images of something) but merely public hallucinations. Something that for many would be very strong evidence for an unobservable entity, it is, for others, not evidence for anything.

\section{Wither Scientific Realism?}

Where does all this leave scientific realism? AC takes it, as he should, that scientific realism is, roughly put, the view that "our best scientific theories and models yield knowledge of both observable and unobservable aspects of the world," 38 where observability is meant to be detectability by the unaided senses. In SO, AC does not offer arguments for scientific realism. The brief of the book is to discuss the nature of the philosophical commitment to scientific realism (and to its rivals, for that matter) and to promote AC's own view that the scope and limits of scientific ontology is a function of the prior adoption of an epistemic stance. In fact, $\mathrm{AC}$ tends to agree with the view that the scientific realism debate has reached an impasse and claims that the impasse is best understood as a conflict between different epistemic stances. ${ }^{39}$ Be that as it may, it seems to me that there are two issues worth considering.

The first relates to the objectivity and factuality of the scientific image. Are the commitments to theoretical/unobservable entities factual (i.e., do they respond to - and are they made true by - an independently given domain of entities)

\footnotetext{
36 Ibid., 226.

37 Ibid., 232.

38 Ibid., 203.

39 See Ibid., 205.
} 
or are they simply a matter of taking a stance that allows talk about such entities without implying or presupposing anything about their objective reality? In other words, are there atoms and their ilk in the world or is there simply a disagreement between rival stances concerning their existence and no further fact of the matter? I honestly do not see an answer to a question like this in SO. My view is that $\mathrm{AC}$ offers no natural way to cut up the scientific ontological commitments into those that are factual and those based on stances. Hence, it's either stances/voluntarism all the way down or there is a fact of the matter all the way up. AC might be tempted to say: they are both! But that doesn't sound quite right, unless taking a stance requires answering to an independently given reality. But, then, stances are true or false, unlike what $\mathrm{AC}$ thinks. Besides, it would then follow that no ontology in, no stance out, which is the exact opposite of AC's motto.

The second issue is this: does the adoption of scientific realism lead to the acceptance of a certain metaphysical theory? Here I am in (almost) full agreement with AC. He says: "It is simply not the case that every last question regarding the ontological natures of things must be settled in order for realism about them to be viable! If it were, the project of scientific ontology would cease before it began." 40 This is sound advice. You don't have to settle all the ontological issues concerning $\mathrm{X}$ in order to be committed to the existence of $\mathrm{X}$. In particular, to be committed to X, you need not be committed to X being in a certain ontic category. Otherwise, the scientific image of the world would not be possible before or independently of having the metaphysical blueprint of the world. In fact, the scientific image and the metaphysical blueprint are made together, putting the latter in the service of the former.

\section{Concluding Thoughts}

In my view, it's a fact that there are electrons and tectonic plates and coronaviruses and social classes, etc., as it would have been a fact, had Antoine Lavoisier been right about the caloric. That we accept that he wasn't and that it is a fact that heat is, by and large, molecular motion, is a tribute to a) the existence of a mindindependent world, which resists our attempts to appropriate it cognitively and shows 'its teeth,' as it were, in producing huge amounts of friction between the way it is and the way we take it to be, and b) science and its collective ability to reveal to us facts about a largely independent world. I wouldn't be so confident about the factuality of (large parts) of metaphysics. I am not so sure, for instance, that whether there are universals is written in the blueprint of the world, though I am more confident that there are laws of nature. All this is, of course, speculation on my part and the reason I speculate is to underwrite the point that a large part of (the attraction of) metaphysics and metaphysical theorizing is (that it is) speculative and explorative.

$40 \quad$ Ibid., 160. 
I take this to be the lasting lesson of Chakravartty's Scientific Ontology, viz., that it opens up a window through which we view and explore our relationship with metaphysics and its relation to science. It's a possible point of view; it's an interesting vantage point; the vistas that open up are bright and rewarding, full of deep thoughts, unexplored trajectories, and good arguments. What more should one expect from a philosophy book? Not much, in my own view. Scientific Ontology is a pleasure to read and to engage with.

\section{Acknowledgements}

A version of this paper was first presented in a 'Chakravartty vs. Psillos' meeting in March 2019, organized by the Rotman Institute of Philosophy - Engaging Science. The audience was so big that furniture had to be removed from the room so that everyone fit (somehow) in. The Q\&A period was awesome with Chris Smeenk, Wayne Myrvold, Robert DiSalle, Jim Brown, and Bill Harper leading the discussion. Many thanks to all participants for a lively discussion. Next, it was presented in an Author meets Critics session of the Pacific APA Conference in Vancouver in April 2019, organized by Kerry McKenzie and chaired by Alan Richardson. Here again, the audience made significant comments. I want to thank them all and especially Anjan for his friendship.

\section{References}

Carnap, R.

1956 "The Methodological Character of Theoretical Concepts," in The Foundations of Science and the Concepts of Psychology and Psychoanalysis, edited by Herbert Feigl and Michael Scriven. Minneapolis: University of Minnesota Press, pp. 36-76.

Chakravartty, A.

2017 Scientific Ontology: Integrating Naturalized Metaphysics and Voluntarist Epistemology. New York: Oxford University Press.

Newton, I.

1729/2016 Mathematical Principles of Natural Philosophy, translated by I. Bernard Cohen, Anne Whitman, and Julia Budenz. Oakland: University of California Press.

Psillos, S.

2004 “Tracking the Real: Through Thick and Thin." The British Journal for the Philosophy of Science 55(3): 393-409.

Psillos, S.

2006 "The Structure, the Whole Structure, and Nothing but the Structure?" Philosophy of Science 73(5): 560-570.

Quine, W.V.

1948 “On What There Is." Review of Metaphysics 2(5): 21-38.

Schindler, S.

2018 Theoretical Virtues in Science. Uncovering Reality through Theory. Cambridge: Cambridge University Press. 
Book Symposium: Anjan Chakravartty's Scientific Ontology 31 van Fraassen, B.C.

1989 Laws and Symmetry. Oxford: Clarendon Press.

van Fraassen, B.C.

2002 The Empirical Stance. New haven and London: Yale University Press. Williams, B.

1973 Problems of the Self. Cambridge: Cambridge University Press. 